\title{
Analysis of System and Resource Information: A Viewpoint
}

\author{
Syafriadi (Corresponding author) \\ Universitas Pembangunan Panca Budi, Medan \\ North Sumatera, Indonesia \\ E-mail: syafriadi_45@yahoo.com
}

Received: January 19, 2017 Accepted: February 18, 2017 Published: March 11, 2017

doi:10.5296/ijhrs.v7i1.10568 URL: http://dx.doi.org/10.5296/ijhrs.v7i1.10568

\begin{abstract}
Development of information resources will lead to changes in the role of managers in decision making, and they are always required to be able to obtain the most accurate information, and the current can be used in the decision-making process. An information system is a combination of work procedures, information, people, and information technology organized to achieve objectives within an organization by providing information for decision makers. In which every manager must manage all information resources effectively and efficiently as possible Because information has Become one of the resources that must be managed properly. The purpose of this research is to find out information about a company's systems, information resources planning and systems of information on information resources can be used to control information management. By limiting the scope of the discussion addressed only Reviews those elements of information systems and information systems role, approach to strategic planning information resources and information systems models of information resources. The results of the study noted that information is an integral part of the (human and equipment) that work together to carry out the processing of the information from the beginning of the collection, processing, storage and distribution, where managers need information before taking a decision. Information is one of the resources that it needs a lot of report manager. With the use of or display of information to reflect the company's physical condition and information resources are managed by the CIO (Chief Information Officer), as manager of information services expertise in solving problems related to sources of information as well as other areas of company operations. The benefit of the company's strategic planning information can find out the important factors needed to develop information systems that are aligned with the corporate strategy since it as well as other resources, the which should be available in all the required information, resources must Also be available when required. So that the necessary information is always available, we need a system that will serve to provide information
\end{abstract}


necessary.

Keywords: Systems, Information systems

\section{Introduction}

\subsection{Background}

The need for information systems in human life is very important. Realized it or not, when the pattern of human life does not systematically arrange, the most MISple goal was not achieved. Here also applies to the world of information. The existence of a variety of information that is circulating in the community is widely supported by the involvement of the system in it and none of the information that emerged and circulated by itself. The progress of computer technology gives the opportunity of providing very great information for decision-makers and technology MISply is one of the four elements of information systems in an organization. For develop information systems then we need to understand the principles, techniques, and notes for system analysis and design so that we can finally understand how to analyze business circumstance roommates logically applies information technology to meet the needs of the company. By the development of information, resources will cause the occurrence of the significant change in the pattern of decision making is done by good management at the operational level (technical Implementers) and the leadership at all levels. Also Reviews These developments have led to changes in the role of managers in decision making; they are always required to be able and to obtain the most accurate and current information that can be used in the decision-making process. Is there any Criteria of information as follows:

1. Accurate $\longrightarrow$ Error-free

2. Complete $\longrightarrow$ Provides all the necessary information

3. Economical $\longrightarrow$ Considering costs and benefits

4. Reliable $\longrightarrow$ Information generated can be reliable

5. Relevant $\longrightarrow$ Information used should be appropriate to the decision-making process

6. MISple $\longrightarrow$ Information generated MISple and clear

7. Timely $\longrightarrow$ Information generated on time

8. Responsive $\longrightarrow$ Information generated can be accountable.

Common information system applied in today's society is a management information system. The superiority of this information system is the coverage of fields is very broad and diverse Compared to other information systems. Management information system is very flexible Because It can be applied anywhere and anytime without being bound by the restrictions of space. Each field requires any profession management information system Because the system is Directly related to a variety of resources used in the profession. Based on the 
background of the issue above, the authors are interested in taking the title of the study: "information systems and information resources."

\subsection{Identification and Limitation of the Problems}

Based on the background of the problem, then the problem can be identified in this paper, as follows:

○ Inadequate implementation of information systems in an enterprise.

○ Inadequate resource planning information.

- Inadequate information about resources information systems can be used to control the management of information.

To clarify the scope of the discussion, then the problems Discussed are limited as follows:

- To know the understanding of information systems, the elements of information systems and the role of information systems.

- To know the approach of strategic planning information resource.

- To find out the models of the system of information resources and information on the type of information required in the management control process

\section{Literature Review}

\subsection{Information Systems}

Definition of the information system is a system. The system has some sense, according to the experts items, namely: According to John M. Echols and Hassan Shadily (Indonesian Language Dictionary United Kingdom-1989) states that: "the system is an arrangement such as that contained regarding the said system means the arrangement of nerve network system, meaning the order of the network and so on." According to M. J. Alexander (1982) stated that "a system is a group of elements of the good shape of physical or non-physical shows a collection of them interconnected and interacting together toward one or more objectives, goals or the end of a system."

Based on the opinions of the experts above we can deduce, the system is a collection of elements that are related to each other to form a single entity in an attempt to Achieve a goal. In the company, is an element of the system is the internal departments, such as the supply of raw materials, production, finished goods inventory, promotions, sales, finance, human resources; as well as external parties such as suppliers and consumers are interlinked with each other and form a unity of effort. Each system usually always has three play elements, input, process, and output.

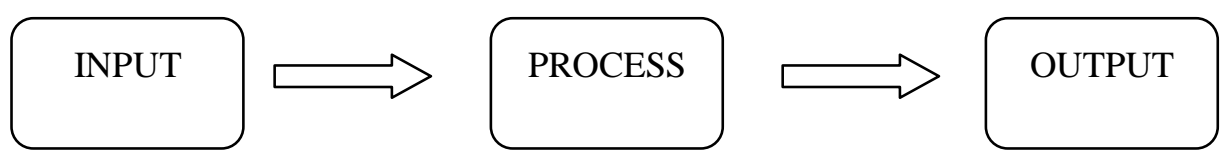

Figure 1. A MISple Model System 


\section{Macrothink}

The information in an organization's role is critical. A system that is less informed will become eventually weak and ended. The information has some sense as follows:

a) "Information as the data that has been processed into a form that is useful to the recipient and the real value that can be understood in the decision now or the future." (Gordon b. Davis, 1974)

b) "Information is something that shows the results of the processing of the data organized and useful to the person who receives it." (Barry E, 1982)

c) "Information as a fact, data, items roommates add knowledge for its users." (Robert N. Anthony and John Dearden,1989)

d) "Information as factor forms that can be used in business decision-making." ( $\mathrm{H}$. Moscove and Mark G. MISkin, 1990)

The sense of the four above it can be concluded that the information was the result of the processing of the data into a more useful for who receives it depicting a real event. Truly is the information system does not always involve; a computer. Information systems that use computer-based information system called Computer (Computer Based Information Systems or CBIS).

The information system is a combination of work procedures, information, people, and information technology organized to Achieve objectives within an organization (Alter, 1992), information systems collect, process, store, analyze, and disseminate information to a specific destination (Turbans, Mc clean, and Wetherbhe, 1999).

The information system is a system in an organization to meet the needs of daily transaction processing, supporting operations, managerial nature, and activities of the strategy of an organization and Provides A Certain outside party with the necessary reports. (Jogiyanto, 2001). According to Burch and Strater in his book "information system: theory and practice." The information system is a set of functions to join as formally and systematically items, namely: Implement a transaction of data processing operations; generate information to support the management in carrying out the activities of planning, control, and decision-making; produces a variety of reports forth e benefit of the external organization. Business practitioners rely on many types of system information using a variety of information technology. For example, some information systems using MISple hardware instructions (paper and pencil) and informal channels information (mouth to mouth). In a MISple system information can be depicted in Figure 2. But not every incoming of data into the system immediately issued information, and the data were being issued as informs again saved for later use that the models of the information system can be extended as shown in the picture below: 


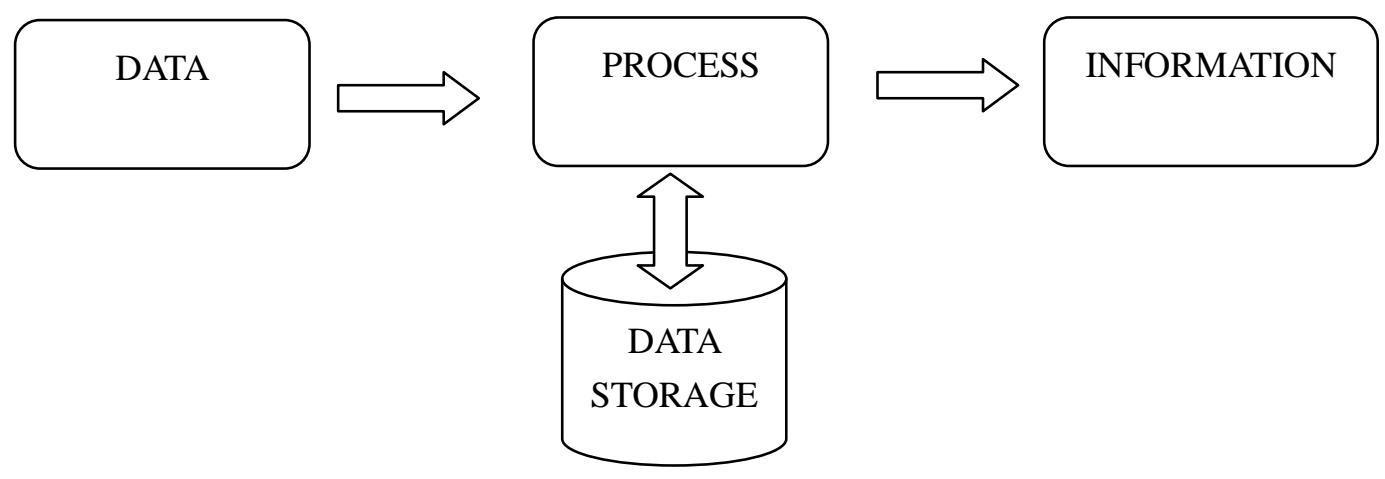

Figure 2: A MISple Model of information system showing the data storage.

2.1.1. Elements of information systems

Information systems as a system has elements of:

- Hardware and Software

- Procedures: a set of rules used to realize data processing to generate the output

- Database: an organizing a set of interrelated data so that the process of information search.

- Computer networks and data communication.

- Brainware

The information system has a lot of ability, where with capabilities are expected to increase of productivity, reduce costs, improve service against the consumer, and not less important is the growth of in decision making. The ability of information systems owned among others:

- Varry out numerical computing, large-volume high speed

- Keep large amounts of information into a small space and easy access.

- Clearly present information.

- To automate manual processes.

- Provide communication within and between the organization that is cheap, accurate, and fast.

Outline information systems are grouped into two; namely information systems used to support operations, and information systems that support management Information systems used to support the operations related to the everyday operating within an organization that is transaction processing, process control, and cooperation between the team/section within an organization as follows:

a) Transaction Processing Systems, for example, process the data the results of business transactions, update the database, the resulting document in an operating business. 


\section{Ml Macrothink}

International Journal of Human Resource Studies

ISSN 2162-3058

2017, Vol. 7, No. 1

b) Process Control System related to the process of supervising and controlling industrial processes, for example, the system of steel production, oil refining with sensors that are connected to the computer.

c) The company supports the cooperation system of communication and teamwork/part/ working group within the organization/company by leveraging electronic and technology, such as e-mail, faxes, teleconferences. This system leads to office automation.

Management Information System (MIS) is an information system used to support management. The output of the Licence in the form of information in the form of reports presented to the particular management level. Because this is one of the Licence information system that supports managerial work, then keep in mind things related to management starts from the division level management until the type of information presented for a particular management level. Those became a critical part, especially if associated with how to design a management information system for organization / agencies / institutions/companies. Management Information System is computer-based system, another network that can provide information for some users to support the functions of management and decision-making functions.

\subsection{Role of Information System}

Information systems have many functions in an organization / institution / corporate all is: Participate in the performance of routine tasks; associate planning, quality, and controls in the system; coordinating and integrating subsystems-subsystem-subsystem subsystems. Also, some usability / functionality of information systems, among others, are as follows:

1) Improve the accessibility of the data presented in a timely and accurate for users, without requiring the presence of mediate information systems.

2) Ensure the availability of quality and skills in utilizing information systems were critical.

3) Develop an effective planning process.

4) Identify skill needs will be supporting information systems.

5) Set the investment that will be directed at information systems.

6) Anticipate and understand the economic consequences of the new information systems and technology.

7) Improve productivity in the application development and system maintenance.

8) Organizations use information systems to process transactions, reduce costs and generate revenue as one of the reviews their products or services.

9) Information systems the Bank uses to process checks-check the client and create a variety of reports current account and transactions that occur.

10) Companies use information systems to sustain the supplies at the Lowest level to be consistent with the type of goods that are available. 


\subsubsection{Information Resources}

The beginning in information management is focused on the data. The venture is in line with the widespread use of database management systems (database management system), or DBMS. The companies reasoned that if they manage reviews their data is by invoking the DBMS based computer, they will mean managing reviews their information. Also, attention should be given to the processing of information that transforms inputs into outputs. That includes processing hardware and software, the people who develop, operate and use the system. It also includes facilities that hold reviews the resources. Facilities reviews these resources that can save one is a computer, as it has been expressed to the experts: "management information system is a computer information systems." (James O. Sob 1987). Information has become one of the resources that must be managed properly, besides other resources-resources. Besides the valuable information too high price, without proper management costs incurred is enormous, but it is not generating, the benefit that is not balanced. There are five types of resources that must be managed by a Manager:

1. Human resources (employees)

2. Natural Resources (material)

3. Machinery, facilities, and energy (technology)

4. Capital (money)

\section{Information (data) conceptual resources}

Every manager must manage all of reviews the resources effectively and efficiently as possible. Four types of resources are the first physical resources while the last resource is a conceptual resource. Conceptual resources are useful in the management of physical resources. The Manager was not only managing the physical resources, but Also conceptual resources. The manager ensures that the necessary raw data is collected and then processed into useful information. Then ascertained who is worthy to Obtain that information in the right form at the right time so that the information can be utilized. The manager is finally disposing of useless information and replace it with an up-to-date and accurate. This whole activity: to obtain information, to use it effectively, and throw it at the right moment is called the information management. Reviews the information resources are managed by the CIO (Chief Information Officer), as manager of information services who donated his expertise in solving problems related to information resources as well as other areas of company operations. $\mathrm{CIO}$ is one of the top-level executives of the company and is responsible for one of the main functional information services roommates are contributing to making important decisions in the company reports Directly to give and executives. The term other than CIO: Director of the MIS, MIS's vice president is a member of the Executive Committee and in collaboration with other executives in strategic planning. The strategic business plan brings together the information as a resource that needs to be used to gain competitive advantage and supported by a strategic plan for information resources. Tasks of a CIO (Chief Information Officer) as follows: 
1) Studied business \& technology

2) Establish partnerships with business unit management \&

3) Focused essential business process fix

4) Estimates the cost of information system in business

5) Build credibility by sending a trusted service.

\subsubsection{Strategic Arrangement Transformation}

Mission, goals, the strategy of the company is the basis of the objectives, constraints, strategies planning system. The process of transformation of the order of group strategy became the order of the strategy planning process named MIS information resources.

\subsubsection{Resources Information System}

Information as a source of strategic information is one source that can generate a competitive advantage by way of focusing on the customer's system build \& information could improve the flow of information between the company and its environment. As with any other resource, the which should be available at all required, information resources must be available when needed. So the information is always available at all it takes, then needed a system that would serve as information whenever necessary. A functioning system provides information for decision-makers is called with information systems. The concept of the achievement of competitive advantage i.e. looked at information resources as a standard competitive advantage, where competitive advantage can be achieved if the establishment of beneficial relationships between the elements; the necessary flow of information with all elements of the environment; the importance of internal operational efficiency. As for the flow of information between companies and customers:

- Information outlining the needs of the product

- Information outlining the use of the product

- Information describing product satisfaction.

\subsection{Security System}

System security objectives (security systems) Refers to the protection of all enterprise information resources from threats by the parties. Security objectives that are intended to Achieve objectives play three items, namely:

- Confidentiality, the company sought to protect the data and information from people who are not entitled.

- The availability, purpose of the CBIS is to provide the data and information to Reviews those who are authorized to use it.

- Integrity, all of the CBIS subsystem must provide an accurate picture of the physical system it represents. 


\subsection{Information Management and Cost reduction strategies}

The most widely utilized strategy is:

1) Consolidation strategies can be followed by reducing the amount of resource location information separately. The reason is that a small number of the centralization of resources that can operate more efficiently than many small resource concentration.

2) Downsizing is the transfer of various applications of computer-based companies from large equipment, such as the configuration of the mainframes to smaller platforms such as mini-computers. In some cases, a lower platform remains in the ER, and in other cases are placed in the user area. Moving to a system that is less expensive but full power is called Smartsizing. Advantages of downsizing: a system that is user-friendly.

3) Outsourcing, a cost-cutting measure could have an impact for downsizing IS greater than on is outsourcing. Outsourcing is rent out all or part of the company's computer operations to service organization outside the company.

Services offered include outsourcers: a) Data Entry and processing is MISple. b) contract programming. c) management facilities, the operation of a computer center. d) systems integration, is the performance of all tasks of system development life cycle. e) support operations for maintenance service or recovery from a disaster.

The advantages of outsourcing, besides reducing costs, as well as the management can focus all Reviews their attention on the development of new strategic systems. Also, outsourcing always gets access to technology and state-of-knowledge without having a full-time staff. The risks of outsourcing, many CIOs feel free to contract to outsource Because long-term does not want to depend on other companies. Also, some companies do not want to submit Reviews their work to outsourcers that have developed sophisticated computing that delivers a competitive advantage.

\section{Discussion}

\subsection{The Information System}

The company's information system is a computer-based system that can perform all the duties of the accounting standards for all organizational units are integrated and coordinated. The existence of the system in human life is critical. Realized it or not, when the pattern of human life does not systematically arrange, the most MISple goal was not achieved. That also applies to the world of information. The existence of a variety of information that is circulating in the community is widely supported by the system's involvement in it. None of the information that emerged and distributed by itself. One of the common information system applied in today's society is a system of information management. The superiority of this information system is the coverage of fields is very broad and diverse Compared to other information systems. Management information system is very flexible Because It can be applied anywhere and anytime without being bound by the restrictions of space. Each field requires any profession management information system because the system is directly 
related to a variety of resources used in the profession.

The MIS companies today accumulate throughout the accounting transaction of data from the manufacturing, sales, purchasing, human resources, and a variety of other business functions. The Data that is associated with the Organization and resources planning can not be done without understanding how each sale, each unit produced, and every action without affecting the overall organization. Information systems company is a large capital expenditure and should be evaluated in the same manner as other significant investments will be undertaken by the organization. Which complicate the investment it is Because such investment requires more than just spending money. The management of the entire organization must be committed to implementing the business process that Allows each other business processes in the organization see and understand the transaction. Sophistication is the fact that many of the advantages of the MIS are not the financial company.

Information systems have many roles in an organization / institution/corporate is: Participate in the performance of routine tasks; Associate planning, quality, and controls in the system; coordinating and integrating subsystems-subsystem-subsystem subsystems. MIS company can be Considered as advanced applications based on database management systems Because The Data is stored on one database, the transaction happened various geographically dispersed operations may be a problem. One thing that is important to the MIS operated by large companies that are geographically dispersed organization requires the latest information technology.

As for the application of the MIS companies Generally, lasts about two years. A long period causes not only the complexity and scope of the project but Also having to deal with legacy systems. The legacy system is a system that carries out Generally core business processes of the company but was developed many years ago and does not include the latest technologies and us. Company information system failure usually includes projects that were abandoned before the application or applied so failed so the Organization back to the information system. That is bad because it costs the organization has invested millions of dollars and many hours of work in the project company's MIS. But the failure of the company's information system does not mean that the organization gives up complet ely. Reviews these organization can be tried again. Organizations can minimize the possibility of failure of the MIS the company take steps

a. Understand the intricacies of the Organization

b. Recognize the process can decrease in value when the standardization imposed

c. Achieving consensus within the organization before deciding to implement a corporate information system

\subsection{Resource Planning Information}

Information can be likened as the blood that flows in the human body, as well as information about a company that is imperative to support the continuity of the process, so there is a reason that the much-needed information for a company. The result when the lack of 
information, within a specified time a company will experience an inability to control the resources so that in taking strategic decisions are very disturbed that will ultimately Defeat in the competitive environment with its competitors. Also, information systems owned Often can not work properly. The main problem is that the system information is too much information that is not useful or meaningful (too many data system). Understand the basic concepts of information is vital in designing an effective information system (effective business system). Setting up the steps or methods in providing quality information is the goal in designing the new system. Output or results from information systems are information. Information can users are categorized into three namely the Manager / Leader, Manager, and people organization or outside of the organization. Information is a resource conceptual and occupies the same level of importance with other physical resources i.e. human, material, machines, and money. Given information is a very important resource where the need is managed as well as possible. The purpose of strategic planning is to develop a strategy whereby an organization would be able to Achieve its goals. Time to strategic planning tends to be long, so fundamental changes in the organization can be held, for example, a retail chain can decide to convert to venture through orders; a convenience store with a store in the city center may decide to change into a close-out store outside the city.

Strategic planning activities should not occur in a cycle of management control activities such as periods. These activities are indeed somewhat irregular, although some strategic planning can be scheduled into the annual planning and budgeting cycle. Some types of data that are useful in strategic planning shows characteristic data:

1) Economic prospects for the areas of activity of the company today.

2) Political environment today and the estimated future

3) The ability and achievements of the organization according to the market, the State, and so on (based on policies nowadays).

4) Projections of future achievements and capabilities according to the market, the State, and so on (based on policies nowadays).

5) The prospects for the industry in other areas.

6) The ability of rivals and their market shares.

7) Opportunities for new ventures.

8) Alternative strategy

9) Resource requirements Projections for some alternative strategies.

Support of information systems for strategic planning could not be as complete as such for management control and operational control. However, management information systems can provide relief on a strategic planning process, for example:

- Evaluation of the ability of the existing internal data is based on a evoke the operational processing needs. 
- Projections of future capabilities can be developed by the data of the past and projected into the future

- Market data and the competition that might be recorded in the database of the computer.

Hence the time for implementation of MIS's company too long for many organization. They may have the market is too volatile, they may be a small organization without sufficient resources to support the project for two years, or they may need to react quickly intervening to support the company's MIS competitors. Whatever the reason, the seller of the ERP should be satisfying customers for the defense industry's phenomenal growth.

\subsection{Information System Resources to control information management}

Information can be likened as the blood that flows in the human body, as well as information about a company that is vital to support the continuity of the process, so there is a reason that the much-needed information for a company. The result when the lack of information, within a specified time a company will experience an inability to control the resources so that in taking strategic decisions are very disturbed that will ultimately defeat in the competitive environment with its competitors. Information is one of the main sources of company information and can be managed just like any other source. And IRM (Information Resources Management) is a life-cycle methodology that is used to create a system that produces high-quality information. The model of the information resources information system is a system that Provides information on the company's information resources to users throughout the company. The information generated by the system information can be useful for management; then the analyst must know the system needs the information it needs, i.e., by knowing the activities for each level (level) management and the type of decisions taken. Based on the above understanding-understanding, then it is seen that the purpose of the establishment management information system or driver's license was so that the Organization has information that is useful in making a management decision, both the involve; routine decisions or strategic decisions. Management information systems supporting functions as planning and controlling.Business objectives for the Organization of the company was a company goal by the original planning, all activities in the operations will always be Involved in the planning process, be it planning a short-term or a long-term plan. Management information systems are highly relevant for the planning function. Planning and controlling are assisted with computer management to widen the conducting this important function. Both functions are very closely related. Without any plan, there will be no control. Whereas if there is no planning control, then the plan will fail. Therefore the value of information is said to be worth when its benefits are more effective than the cost to get it and most of the information can not be precise dates, to his advantage with a unit of monetary value but can be estimated the value of its effectiveness, so information systems for information management control, management control is required by department managers to measure job, Decide control measures, formulate new decision rules to apply to operational personnel, and allocate a longer resource. Management control process requires the following types of information: Planned Work (standards, expectations, budgets, etc.); deviations from 


\section{Macrothink}

International Journal of Human Resource Studies

ISSN 2162-3058

2017, Vol. 7, No. 1

the planned work; to irregularities; analysis of the decision or direction of the actions. Database for management control play consists of two elements: (1) the database of operational, and (2) plan, budget, standard, etc. that defines an estimate on implementation, as well as some external data is such as comparative industry and cost indices. Processes to support the decision of management control activities is as follows:

1) Model of planning and budget

2) Deviation reporting programs

3) Problem analysis models

4) Decision models

5) Examination of the models/questions

The output of the control system of information management is the plan and budget, scheduled reports, special reports; analysis situates issue, the decision to study, and answers to questions. The efforts needed to achieve a successful Information Resources Management are:

a. Companies are trying to use the information to Achieve competitive advantage

b. Executives should be aware that the Ministry of Information as a functional area.

c.Executives have to Recognize the existence of the CIO / Chief Information Officer.

d. Executives must enter the information in the resources planning strategy

e. The existence of a formal strategy planning for other sources of information.

f. Planning strategy as well to set up the user's computer.

\section{Conclusion \& Suggestions}

\subsection{Conclusion}

Based on the discussion in the previous chapters, then it can be taken a few summary as follows: Information is an aggregation element (human and equipment) are cooperating to implement the information processing of started collecting, processing, storing up to distribute, where a Manager requires information before he takes a decision. Information is one of the resources needed a Manager. By using many reports or displays information to reflect the physical condition of the company. Reviews These information resources are managed by the CIO (Chief Information Officer), as manager of information services who donated his expertise in solving problems related to information resources as well as other areas of company operations. Information strategy planning benefits i.e. parties companies can know the important factors needed to develop an information system that is aligned with corporate strategy. As with any other resource, the which should be available at all required, information resources Also must be available when needed. So the information is always 
available at all it takes, then needed a system that would serve as information necessary.

\subsection{Suggestions}

The use of management information systems is highly relevant for the planning function. Planning and controlling are assisted with computer management to widen conducting this important function. Both functions are very closely related. Without any planning, control would not exist. Whereas if there is no planning control, then the plan will fail so must be well managed. Information resources must be available when needed. So the information is always available at all it takes, then needed a system that would serve as information necessary. How the procurement of information systems there are three ways:

1) Create your own

2) Purchase of software that is already so

3) Outsourcing: submit a development system to outside parties

Each way has advantages and disadvantages can, therefore, be made as consideration for the organization to select the procurement information system appropriately and wisely.

\section{References}

Antony N. Robert N. and John Dearden, (1989), Management Control System.

B. Gordon B. Davis, (1999), Management Information System, 7th edition, New York: McGraw-Hill Book Company.

Chushing E.Barry E., (1982), Information Systems and Business Organization.

---------, (2001), Kerangka Dasar Sistem Informmasi Manajemen: Struktur dan Pengembangan, Jakarta: Pustaka Binaman Pressindo.

Moscove \& Simkin G. Mark, (1990), Accounting Information System: Concepts and Practice.

Siagian ,SP., (1994), Sistem Informasi untuk Pengambilan Keputusan, Jakarta: PT. Gunung Agung.

, (1995), Filsafat Administrasi, Jakarta: PT. Gunung Agung

Terry R. George, (1977), Principles of Management, Richard D. Irwin Inc.

http://masdevid.blogspot.com/2009/02/pengertian-sistem-informasi manajemen.html

\section{Acknowledgement}

I gratefull acknowledge to financial support from Universitas Pembangunan Panca Budi and I I would like to gratefully and sincerely thank M. Dharma Tuah Putra Nasution for his helpful and guidance. 


\section{Macrothink}

International Journal of Human Resource Studies

ISSN 2162-3058

\section{Copyright Disclaimer}

Copyright for this article is retained by the author(s), with first publication rights granted to the journal.

This is an open-access article distributed under the terms and conditions of the Creative Commons Attribution license (http://creativecommons.org/licenses/by/3.0/). 